\title{
ACROMIOCLAVICULAR AND CORACOCLAVICULAR RECONSTRUCTIONBY NYLON TAPE VERSUS CORACOCLAVICULAR SCREW IN MANAGEMENT OF ACUTE ACROMIOCLAVICULAR DISLOCATION
}

\author{
Tarek Mohammed Khalil, Maged Mohamed Samy Abou Elsoud, Wael Ahmed \\ Mohammed Nassar, Mohamed Hassan Sobhy, Ashraf Mohammed El Seddawy and \\ Ahmed Eid Morsy Khaled
}

\author{
Department of Orthopedic \\ Surgery, Faculty of medicine, \\ Ain Shams University. \\ Cairo, Egypt \\ Corresponding : \\ Ahmed Eid Morsy Khaled \\ El Mihi \\ Mobile : 01001859112 \\ E mail: \\ ahmed888n@yahoo.com \\ Received: 19/12/2019 \\ Accepted: 23/1/2020
}

Online ISSN: 2735-3540

\begin{abstract}
:
Background \& Purpose: A number of different surgical techniques were described to treat acute acromioclavicular (AC) joint dislocations which aim to restore joint congruity and mechanical stability. The purpose of this study was to compare functional, radiological outcomes and fixation related complications of acromioclavicular and coracoclavicular (CC) reconstruction by nylon tape versus coracoclavicular screw in management of acute acromioclavicular dislocation.
\end{abstract}

Patients \&Methods: In the periodfrom September 2017 to December 2019, a prospectiverandomized controlled clinical trial was conducted in Ain Shams University hospitals including 30 cases with types III and V AC injuries. They were divided into two groups, 15 patients underwent $A C$ and $C$ Creconstruction by nylon tape (Group A) and the other 15 patients underwent coracoclavicular screw (Group B).The patients were evaluated forpain, range of motion (ROM), radiologic findings (CC distance difference between both sides was measured), American Shoulder and Elbow Surgeons (ASES), and Constant scores. Postoperative complications were recorded and assessment of time of returning to the work was done. The evaluation was done preoperatively and each time of follow up with a minimum period of one year.

Results: After a mean follow up period of $15 \pm 2.7$ months for group A and 14.37 \pm 4.74 months for group B, patients of both groups showed highly significant improvement between mean preoperative and postoperative pain, ROM, Constant, ASES scores and CC distance difference. Group A showed better results as regard mean postoperative ROM, Constant score and ASES score than group B, while group $B$ showed better results as regard mean postoperative pain score and CC distance difference. However, there was no statistically significant difference between the 2 groups.

In group A the mean post-operative pain and ROM scores (both as a part of constant score) was $12.67( \pm 3.2)$ and $33.53( \pm 2.9)$ respectively while in group $B$ was $12.92( \pm 3.34)$ and $32.83( \pm 2.98)$ respectively. The mean post-operative Constant and ASES scores was $86.93( \pm 7.22)$ and $89.93( \pm 7.5)$ respectively for group A and 86.17 $( \pm 8.33)$ and $87.58( \pm 6.08)$ respectively for group B. Radiographic CC distance difference $(\mathrm{mm})$ between both shoulders at one year postoperatively was 2.27 in group A and 2.13 in group B. There was a 
statistically significant difference between the mean time to return to work for patients in group A (3.2 months) and patients in group B (4.2 months). Complete loss of reduction occurred in three patients in group $B$, two cases of subluxation (50\% of the preoperative CC distance difference) in group $A$, one case of wound infection in each group and one case of fracture clavicle in group $B$.

Conclusion: Both AC and CC reconstruction by nylon tape and CC screw procedures are valid surgical options and have adequate outcome in treatment of patients with acute AC dislocation. However there are some concerns about the failure rate and the need of another operation for screw removal that was present in CC screw group which affects patient satisfaction in that group.

Keywords: acromioclavicular dislocation, coracoclavicular screw, nylon tape, coracoclavicular ligament.

\section{INTRODUCTION:}

Acute acromioclavicular separation is a common injury among young individuals following a direct trauma to the shoulder or a fall on outstretched hand with the arm adducted $^{(\mathbf{1})}$. AC joint dislocations account for $12 \%$ of all dislocations about the shoulder and are 5 times more common in males than in females ${ }^{(2)}$.

Although this injury is highly prevalent, there is no consensus about its optimal treatment. Over 100 different techniques for surgical treatment of acute AC joint dislocations have been described. All techniques attempt to restore joint congruity and mechanical stability in order to provide optimal preconditions for the healing by rigid scar tissue ${ }^{(3)}$.

Commonly used methods include fixation of the $\mathrm{AC}$ joint with a K-wire or hook plate ${ }^{(4)}$, dynamic muscle transfer ${ }^{(5)}$, fixation between the clavicle and the coracoid with the use of a coracoclavicular screw, Weaver-Dunn procedure ${ }^{(6)}$ and coracoclavicular (CC) ligament reconstructtion by grafts ${ }^{(7)}$, endobuttons, nonabsorbable sutures $^{(8)}$ or tight rope ${ }^{(9 \& 10)}$.

Coracoclavicular stabilization with a lag screw was described by Bosworth in 1940s. ${ }^{(11)}$ The mechanical performance of CC screw fixation was closest to that of the native $\mathrm{CC}$ ligament. Its ultimate strength was $80 \%$ higher than that in the intact ligament. However, a second surgical procedure for screw removal is needed ${ }^{(12)}$

Previous biomechanical studies have shown that four components of the AC capsular ligaments and two components of the $\mathrm{CC}$ ligaments contribute to $\mathrm{AC}$ joint stability depending upon the direction and magnitude of the force applied. The trapezoid ligament provides the major support against compressive loads applied along the axis of the clavicle and acts as a secondary restraint to superior translation. On the other hand, the conoid ligament contributes to both superior and anterior stability $^{(13)}$.

Among the 4 AC capsular ligaments, the superior and posterior capsular ligaments, reinforced by the deltoid and trapezius muscle, are important due to their primary role in prevention of posterior translation $^{(13)}$.

To achieve reduction of an $\mathrm{AC}$ joint separation, novel techniques aim to restore maximum stability and early function by restoring the native $\mathrm{AC}$ and $\mathrm{CC}$ anatomy without the use of any metal fixation which can be done by nylon tape ${ }^{(14)}$.

A major advantage of this technique is that it provides anatomic stabilization of 
both injury components with a simple technique that can be performed without the need for expensive tools. In addition, it carries a low risk of migration, breakage, hardware problems and does not require removal of hardware ${ }^{(\mathbf{1 4})}$. However, in terms of strength sling technique demonstrates less than $30 \%$ the stiffness of the native $\mathrm{CC}$ ligament ${ }^{(12)}$.

\section{PATIENTS \& METHODS}

A prospective randomized controlled clinical trial study was performed on 30 cases (25 males and 5 females) with acute AC injuries treated from September 2017 to December 2019. They were divided into two equal groups: group $\mathrm{A}$ underwent $\mathrm{AC}$ and $\mathrm{CC}$ reconstruction by nylon tape and group B underwent coracoclavicular screw. Patients were randomly distributed among the two groups using computer generated randomization by Random Allocation Software.Only acute cases of Rockwood types III and V were included in this study. Patients with evidence of AC arthrosis, associated injury of the upper limb that may alter with rehabilitation and cervical radiculopathy were excluded from the study.

The mean age of the patients at the time of diagnosis in group A was 33.9 years and in group B was 30.4 years. The right shoulder was affected in 17 (56.7\%) patients and it was the dominant side in all of them. The left shoulder was affected in 13 (43.3\%) patients and it was the dominant side in 2 of them. Road traffic accidents were the cause of the dislocation in 18 patients, direct fall on the shoulder in 9 patients and indirect trauma (fall on outstretched hand) in 3 patients. The mean duration from the onset of trauma to the date of surgery was 6 days (range, 2-17 days).

All patients were evaluated preoperatively by history taking, mode of trauma, clinical examination, Constant score, and ASES score. Plain x-rays were done with antero-posterior (showing both shoulders), Zanca and axillary lateral views. 20 patients found to be type $\mathrm{V}$ AC dislocation (11 in group A and 9 in group B) and 10 patients were type III (4 in group A and 6 in group B) according to Rockwood classification. CC distance difference (between the upper border of the coracoid process and the inferior cortex of the clavicle) between the two sides was measured.Immediate post-operative X-ray films were done. Patients were asked to visit outpatient clinics, 2 weeks, 6 weeks, 3 months and 1 year after the operation and were assessed clinically and radiographically and rescored with the same scores. Any complication during the surgery or in the postoperative period was reported and analyzed.

\section{Operative technique:}

Under general anesthesia, the patient was placed in the beach-chair position. An anterosuperior transverse skin incision is made, starting lateral at the $\mathrm{AC}$ joint and ending medial at the junction of the outer and middle thirds of the clavicle. The deltoid muscle (with the attached periosteum) was elevated off the anterior edge of the distal third of the clavicle. The deltoid was slightly inferiorly retracted until the coracoid process was exposed.

In group $A$ (AC and $\mathrm{CC}$ reconstruction by nylon tape), the clavicular insertions of the trapezoid and conoid ligaments are identified and marked on the upper clavicular surface with cautery. Similar technique as that described by Sobhy ${ }^{(14)}$ was done where a nylon tape 70 $\mathrm{cm} \times 6 \mathrm{~mm}$ (Ethicon) is passed around and flushes with the coracoid base by use of a right-angled clamp from the medial to lateral aspect. Two drill holes are made with a 2 $\mathrm{mm}$ drill bit at the conoid and trapezoid points from the superior to inferior aspect of the clavicle. The conoid hole is medial and posterior, usually $45 \mathrm{~mm}$ from the lateral end clavicle. While, the trapezoid hole is 
lateral and central, usually $25 \mathrm{~mm}$ from the lateral end clavicle. Both nylon tape ends are passed through these holes (figure 1). After reduction of the $\mathrm{AC}$ joint, the nylon tape ends are tied above the clavicle, leaving one limb of the tape long enough for the rest of the procedure.
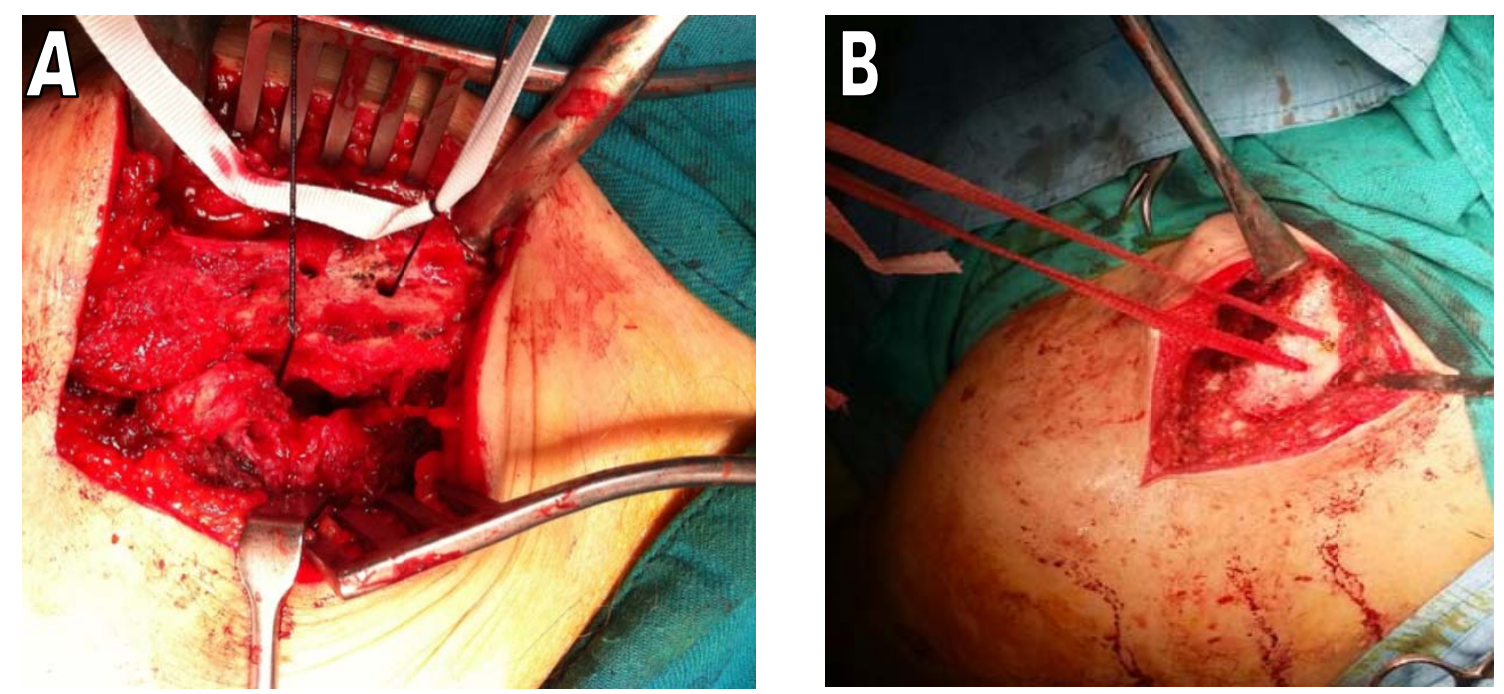

Figure 1: A)Conoid and trapezoid tunnels with the passage of vicryl sutures. B) Relay of nylon tape through the tunnels.

A third drill hole is made through the acromion from the superior to anterior aspect $(1 \mathrm{~cm}$ lateral to the $\mathrm{AC}$ joint) and a fourth drill hole made through the clavicle from anterior to superior $(1 \mathrm{~cm}$ medial to the $\mathrm{AC}$ joint). The remaining long limb of the nylon tape is passed through the third hole as a superior AC ligament. Then, it is passed through the fourth hole anterior to the $\mathrm{AC}$ joint as an anterior AC ligament to make a second knot with the other limb of the tape (figure 2 and 3 ).
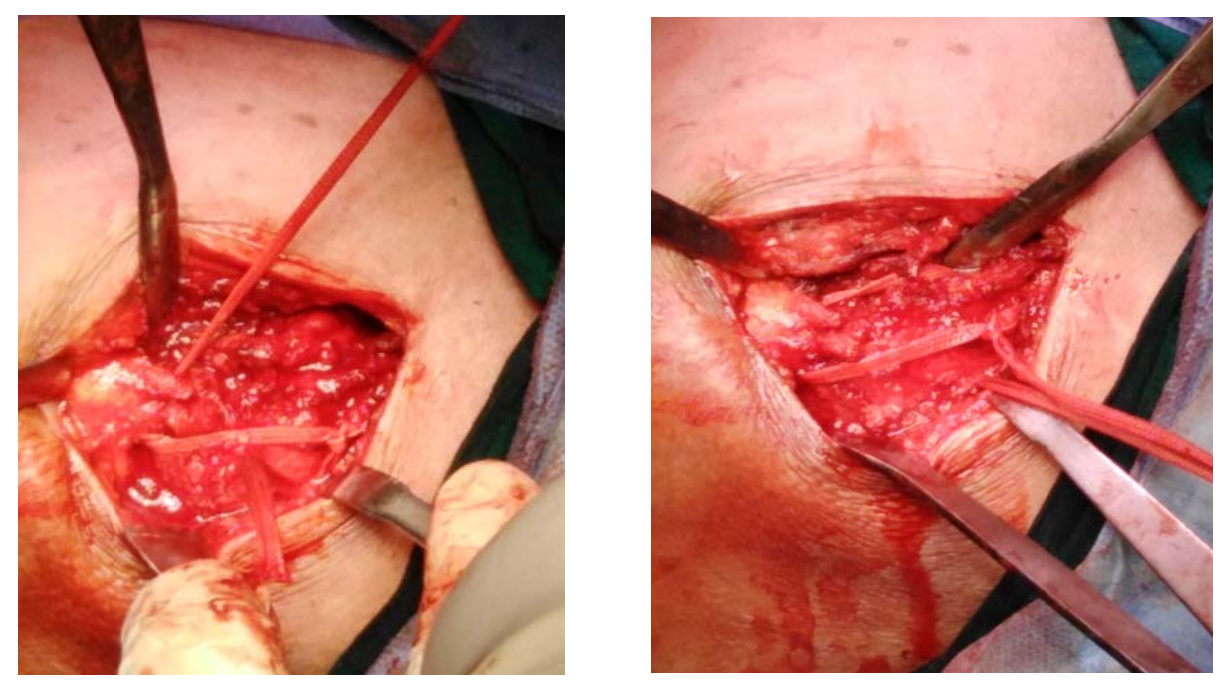

Figure 2: Reconstructing AC ligaments. 

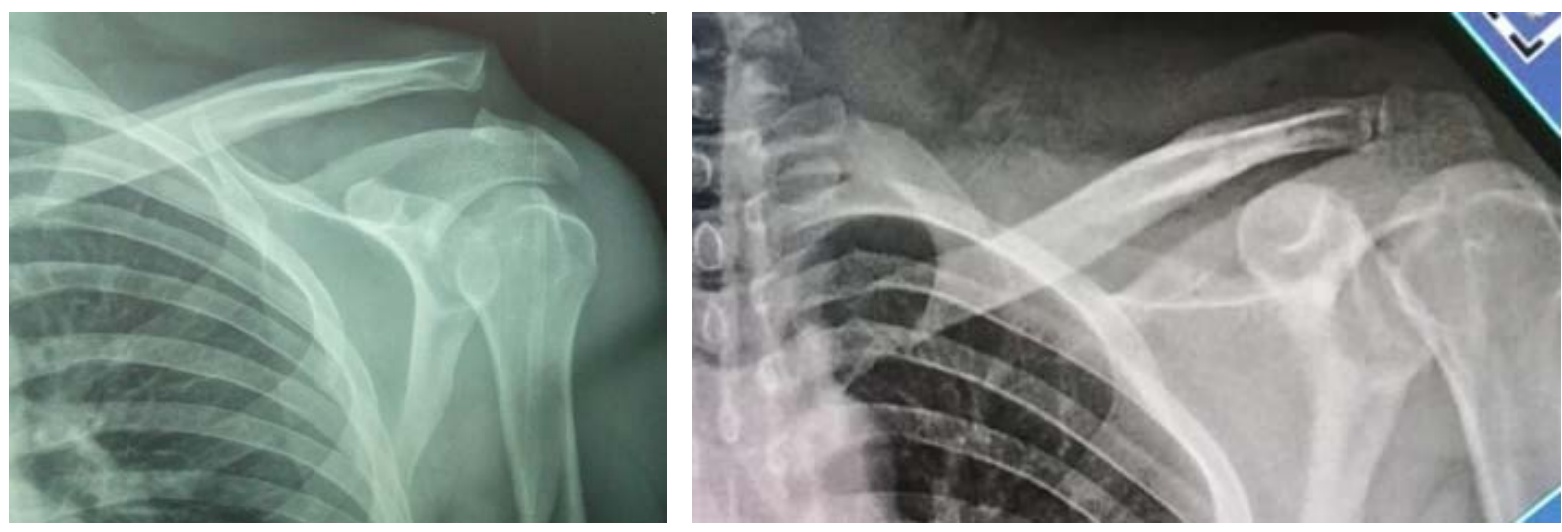

Figure 3: Pre and postoperative X-rays of left AC dislocation with the use of nylon tape technique.

In group B (CC screw), Reduction of the AC Joint is done. The guide wire of the cannulated screw is passed from superior surface of the clavicle to the base of the coracoid, followed by a cannulated drill bit. Measurement of the length of a suitable screw is performed using the depth gauge. A partially threaded cancellous screw of a suitable length and a washer is then inserted. The screw is removed after 8-12 weeks by a minor operation (figure 4). CC screw was first introduced by Bosworth ${ }^{(11)}$ in 1941.
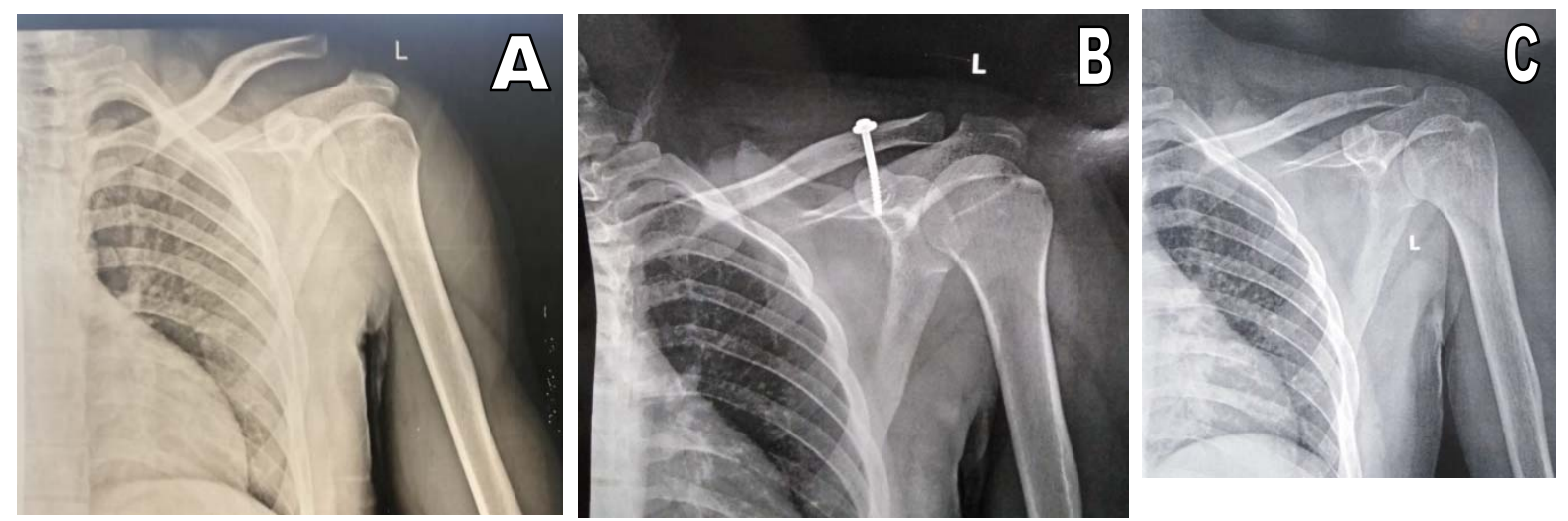

Figure 4: a) Radiograph showing a type V AC dislocation. Radiographs obtained (b) following screw fixation and (c) screw removal.

In all patients, If possible, the CC ligaments are repaired. Repair of all soft tissues including AC ligaments, deltoid, and trapezius tears is then performed. The deltoid fascia and subcutaneous tissue are carefully closed, followed by skin closure.

Pendulum exercises, shrugging of shoulders, elbow flexion/extension, forearm supination/pronation and active hand and wrist motion were encouraged immediately after surgery. In the first 4 weeks, the extremity is put in a sling but the patient is allowed to perform passive range of motion as tolerated, along with the previous exercises. From 5 to 10 weeks, the patient discontinues use of the sling and starts active ROM as tolerated, as well as active assisted strengthening exercises. From 11 to 16 weeks, the patient gradually regains full ROM and muscle strengthening exercises in all planes. Return to work was allowed according to the progression of each patient in rehabilitation pathway.

\section{Statistical analysis:}

Analysis of data was done using SPSS program version 23 . To describe the studied sample, quantitative data were presented as 
minimum, maximum, mean and standard deviation. Qualitative data were presented as count and percentage. Student $t$ test was used to compare quantitative data between the two groups. Chi-Square test and Fisher Exact test were used to compare qualitative data between both groups. Paired sample $t$ test and Repeated Measure ANOVA test were used to compare quantitative data at different time points for the same group. Repeated Measure ANOVA test was used also to compare change in quantitative data over time between different groups. $\mathrm{P}$ value $\leq 0.05$ was considered significant.

\section{RESULTS:}

The mean follow up period was $15 \pm 2.7$ months for group A and 14.37 \pm 4.74 months for group B. Pain was assessed as a part of Constant score (table 1), Group B showed better one year postoperative pain relief however the difference was not statistically significant between both groups (p-value =0.85). There was a statistically highly significant improvement ( $\boldsymbol{p}$-value $<\mathbf{0 . 0 0 1})$ between the pre-operative and one year postoperatively in both groups.

Range of motion measured by a goniometer and scored as part of the Constant score (table 1). Group A showed better one year postoperative ROM improvement however the difference was not statistically significant between both groups ( $\boldsymbol{p}$-value $=\mathbf{0 . 5 4})$. There was a statistically highly significant improvement ( $p$-value $<0.001)$ between the pre-operative and one year postoperatively in both groups.

Table 1: Comparison between both groups regarding pain and ROM scores.

\begin{tabular}{|l|c|c|c|c|c|}
\hline \multirow{2}{*}{} & \multicolumn{2}{|c|}{ Group I } & \multicolumn{2}{c|}{ Group II } & $\begin{array}{c}\text { Postop. P-value } \\
\text { between both groups }\end{array}$ \\
\cline { 2 - 5 } & Mean & SD & Mean & SD & \\
\hline Pre-operative pain & 3 & 2.54 & 3.67 & 2.29 & \multirow{2}{*}{0.85} \\
\hline 1 year post-operative pain & 12.67 & 3.2 & 12.92 & 3.34 & \\
\hline Pre-operative ROM & 15.87 & 4.09 & 16.07 & 5.11 & \multirow{2}{*}{0.54} \\
\hline 1 year post-operative ROM & 33.53 & 2.9 & 32.83 & 2.98 & \\
\hline
\end{tabular}

Regarding functional scores (table 2), group A showed better one year postoperative Constant and ASES scores however the difference was not statistically significant between both groups (p-value $=$
0.8 \& 0.39 respectively). There was a statistically highly significant improvement (p-value $<0.001$ ) between the pre-operative and one year postoperatively in both groups.

Table 2: Comparison between both groups regarding Constant and ASES scores.

\begin{tabular}{|l|c|c|c|c|c|}
\hline \multirow{2}{*}{} & \multicolumn{2}{|c|}{ Group I } & \multicolumn{2}{c|}{ Group II } & $\begin{array}{c}\text { Postop. P-value } \\
\text { between both groups }\end{array}$ \\
\cline { 2 - 5 } & Mean & SD & Mean & SD & \\
\hline Pre-operative Constant & 32.87 & 6.95 & 36.60 & 8.50 & \multirow{2}{*}{0.8} \\
\hline 1 year post-operative Constant & 86.93 & 7.22 & 86.17 & 8.33 & \\
\hline Pre-operative ASES & 30.40 & 5.50 & 31.93 & 5.31 & \multirow{2}{*}{0.39} \\
\hline 1 year post-operative ASES & 89.93 & 7.50 & 87.58 & 6.08 & \\
\hline
\end{tabular}

Radiologic assessment (table 3)showed better one year postoperative $\mathrm{CC}$ distance difference $(\mathrm{mm})$ in group B however the difference was not statistically significant between both groups $(\boldsymbol{p}$-value $\mathbf{= 0 . 8 6})$. There was a statistically highly significant improvement ( $\boldsymbol{p}$-value $<\mathbf{0 . 0 0 1}$ ) between the pre-operative and one year postoperatively in both groups. 
Table 3: Comparison between both groups regarding $\mathrm{CC}$ distance difference.

\begin{tabular}{|l|c|c|c|c|c|}
\hline \multirow{2}{*}{ CC distance difference } & \multicolumn{2}{|c|}{ Group I } & \multicolumn{2}{c|}{ Group II } & $\begin{array}{c}\text { Postop. P-value } \\
\text { between both } \\
\text { groups }\end{array}$ \\
\cline { 2 - 5 } & Mean & SD & Mean & SD & \\
\hline Pre-operative & 12.20 & 4.04 & 10.80 & 3.43 & \multirow{2}{*}{0.86} \\
\hline 1 year post-operative & 2.27 & 1.44 & 2.13 & 2.42 & \\
\hline
\end{tabular}

There was a statistically significant difference between the mean time to return to work for patients who underwent $\mathrm{AC}$ and $\mathrm{CC}$ reconstruction by nylon tape (3.2 months), and the mean time to return to work for patients who underwent $\mathrm{CC}$ screw fixation (4.2 months) ( $\boldsymbol{p}$-value $=\mathbf{0 . 0 3})$. The mean time to return to work for the $\mathrm{CC}$ screw group was longer by about one month.

Results showed better mean postoperative pain, ROM, Constant and ASES scores in males than females. However, results were only significant regarding ROM and ASES score (P-value= $0.04,0.01)$ respectively. Nineteen dominant and 11 non-dominant sides were included in this study. Results showed better mean postoperative pain, ROM, Constant and ASES scores in the non-dominant side, but differences did not reach statistical significance except in ASES score which was significant $(\boldsymbol{P}$-value $=\mathbf{0 . 0 4})$. Twenty manual workers and 10 involved in sedentary work were included in the study. Results were better in sedentary work patients; however, the difference was not statistically significant.

The mean operative time for nylon tape procedure was 62 mins and the mean operative time for CC screw operation was 48 mins. Nylon tape procedure had longer operative time, the difference was statistically highly significant, (p-value $<0.001$ ).

Complete loss of reduction occurred in three patients, all in group B (CC screw) with backing out of the screw. Revision operation done for two of them and the third refused to do operation. 2 cases of subluxation (partial loss of reduction, $50 \%$ of the preoperative CC distance difference), all occurred in group A (nylon tape) with no further intervention needed.

Two cases with wound infection, one in group A managed by wound dressing and intravenous antibiotics till improvement. Frozen shoulder occurred in the same case and was treated by physiotherapy. The other case in group B needed debridement twice. Fracture clavicle occurred in the same case and was treated by distal clavicle plate fixation and iliac bone graft. One case of CC ossification in group B.

\section{DISCUSSION:}

Although there are numerous procedures described for surgical treatment of acromioclavicular joint dislocations, there is still no gold standard and no clear agreement about the superiority of one technique versus another. The main goal of treatment for $\mathrm{AC}$ injuries are achieving painless range of motion of the shoulder, obtaining full strength, and achieving no limitation in activity.

In this study, two techniques were used to stabilize the AC joint that can be performed in any operating room without the need for expensive tools. In the first group, the sling technique was used using nylon tape to reconstruct both the $\mathrm{AC}$ ligaments and the $\mathrm{CC}$ ligaments. It does not involve the use of metal implants, which require later removal. Nylon tape was inserted in a 
position similar to the former conoid and trapezoid ligaments with the addition of reconstructing the $\mathrm{AC}$ ligaments as described by Sobhy ${ }^{(14)}$.

In the second group, a CC screw was used which was popularized by Bosworth ${ }^{(11)}$ in 1941. The strength of the coracoclavicular screw is $80 \%$ greater than that of the original ligament when it is placed bicortically. However, one of the disadvantages is the need for a second operation for its removal.

The aim of this study is to compare functional, radiological outcomes and fixation related complications between the two groups in management of acute acromioclavicular dislocation.To our knowledge there is a little or may be no clinical prospective studies comparing both techniques in management of AC dislocation from the functional $\&$ radiological points of view, but there are studies which analysed outcomes of each technique of management separately.

Esenyel et al (2010) performed the CC screw technique in 32 patients with types (III to VI) AC dislocation with mean age of 35 years. The screws were removed after 8 weeks postoperatively. The mean Constant score was 98 (range 92 to 100). There was subluxation of the AC joint in one patient (3.3\%). Two patients developed redislocation due to screw cut out and underwent reoperation with another screw fixation. None of the patients showed joint degeneration. ${ }^{(10)}$

EL-Menawy (2014) did CC screw in 20 patients with $\mathrm{AC}$ dislocation. The mean age of the patients was 32 years. The mean follow up was 18 months. According to Constant score, 14 patients had an excellent score (>89), four had a good score (80-89), two had a fair score (70-79), and there were no poor results $(<70)$. Implant failure with backing out of the screw occurred in one patient; a superficial wound infection occurred in three patients and required no further surgical treatment. Shoulder stiffness was mild in two patients and did not affect the patient's daily activities. ${ }^{(15)}$

Sobhy (2012) did a prospective caseseries study on 17 cases with a mean age of 31 years treated by anatomic reconstruction of the AC ligaments and $\mathrm{CC}$ ligaments using nylon tape with a mean follow up period of 28 months. Patients showed statistically significant improvements in the mean VAS score (from 6.4 to 2.4 points), ASES score (from 25.3 to 81.7 points), and Constant score (from 21.2 to 84.9 points). In addition, patients showed statistically significant improvements in ROM scored as part of the Constant score (from 11.5 to 27.4 points). Radiographic superior displacement showed reduction from 13 to $2 \mathrm{~mm}$ which was statistically significant. There was 1 case of recurrent subluxation. ${ }^{(14)}$

Greiner et al (2009) made a retrospective study about mid- to long-term results of the clinical and radio graphical results after open reduction and stabilization of AC dislocations using polydioxanesulfate (PDS) cerclage augmentation. 50 patients with a mean age of 35 years were treated of type III to V AC dislocation. The average follow up period was 70 months. The mean constant score was 91.7. Radio graphically, $80 \%$ showed a difference of CC distance in comparison to the contra lateral side of $<5$ $\mathrm{mm}, 14 \%$ of $5-10 \mathrm{~mm}$ and $6 \%$ of $>10 \mathrm{~mm}$. Complications were: one superficial wound infection, one extensive coracoclavicular calcification and two complete secondary redislocations. ${ }^{(16)}$

Sharabi et al (2017) did a prospective randomized evaluation on 47 patients. Group A $(\mathrm{N}=24)$ was managed with reconstruction of the $\mathrm{CC}$ and $\mathrm{AC}$ ligaments by means of loop fixation (Dacron tape and No. 5 Ethibond suture). In group $\mathrm{B}(\mathrm{N}=23)$, a $\mathrm{CC}$ screw was added to the loop fixation. The mean follow-up period was 24.2 months for group A and 23.3 months for the group B. No statistically significant difference was 
found between the results of the two groups. The mean postoperative pain score (visual analog scale) was $1.38 \pm 1.7$ for group I and1.35 \pm 1.27 for group II. The mean Constant score was $90.2 \pm 8.1$ for group I and $92.2 \pm 5.5$ for group II. The mean coracoclavicular distance difference $(\mathrm{mm})$ $2.17 \pm 1.3$ in group A and $1.7 \pm 1.5$ in group B. Recurrence was detected in four patients, two in each group. ${ }^{(8)}$

\section{In our study:}

A randomized controlled study was conducted on 30 patients with type III and V $\mathrm{AC}$ dislocation. 15 of them underwent $\mathrm{AC}$ and $\mathrm{CC}$ reconstruction by nylon tape (Group A) and the other 15 patients underwent coracoclavicular screw (Group B).

The mean age at time of surgery was 32 years old (range from 21 to 53 years). Regular outpatient follow-up was done with a mean follow up period $15 \pm 2.7$ months in group $\mathrm{A}$ and $14.37 \pm 4.74$ months in group B.As regard the operation time, it was found that mean operative time in group B (48 mins) shorter than that of the group A (62 mins) which was statistically significant.

At the final follow up, there was significant pain improvement in both groups. Although, group B showed better postoperative pain score, this difference was not statistically significant. There was statistically significant improvement in range of motion in both groups at final follow up. Group A showed better postoperative ROM score; however, the difference between both groups was not statistically significant.

Regarding functional outcome measures (Constant and ASES scores), they showed improvement as well which was statistically significant within each group. Higher scores were present in group $\mathbf{A}$ but with no statistically significant difference between both groups. There was a statistically significant difference in the mean time to return to work between both groups. The mean time to return to work for the $\mathrm{CC}$ screw group was longer by about one month.

Statistically significant difference occurred in CC distance difference between preoperative and last follow up in both groups. Group B showed better improvement but with no statistically significant difference between both groups. Partial loss of reduction was noticed to occur gradually in nylon tape group which is in most cases is within 1-3 $\mathrm{mm}$ except 2 cases with subluxation (partial loss of reduction, $50 \%$ of the $\mathrm{CC}$ distance difference in preoperative $\mathrm{X}$-rays).

As regard complications, complete loss of reduction happened in 3 cases of $\mathrm{CC}$ screw group with screw back out which needed revision surgery, while subluxation occurred in two cases of group A which did not need further intervention. One case of $\mathrm{CC}$ ossification in $\mathrm{CC}$ screw group. One case of wound infection which needed debridement twice and lateral end clavicle fracture occurred in the same case which was fixed by plate and iliac bone graft. One case of superficial infection in nylon tape group treated with wound dressing and antibiotics and the same case suffered from frozen shoulder treated by physiotherapy.

Group B need another operation to remove the screw (8-12 weeks postoperatively) which lead to less satisfaction in patients of that group; also, another hospitalization and further medical expenditures are needed.

Our study had some limitations including the small number of patients, the need for longer follow up for better assessment of $\mathrm{AC}$ arthritis and clavicle osteolysis. Parts of the functional scores were verbally translated and lacked cultural adaptation.

\section{Conclusion:}

Both $\mathrm{AC}$ and $\mathrm{CC}$ reconstruction by nylon tape and $\mathrm{CC}$ screw procedures are valid surgical options and have adequate 
outcome in treatment of patients with $\mathrm{AC}$ dislocation. They both offer cheap, easy and available implants. However there are some concerns about the failure rate as a drawback in CC screw technique, Also, the need of another operation for screw removal led to less satisfaction in this group.

\section{REFERENCES:}

1. Elgohary HS, Selim NM. Mini-open approach for stabilization of acute complete acromioclavicular dislocation. Egypt Orthop J 2014; 49:320-325.

2. Fraser-Moodie JA, Shortt NL, Robinson $\mathrm{CM}$. Injuries to the acromioclavicular joint. J Bone Joint Surg [Br] 2008; 90: 697-707.

3. Weiser L, Nuchtern JV, Sellenschloh K, Puschel K, Morlock MM, Rueger JM, Hoffmann M, Lehmann W, Grobterlinden LG. Acromioclavicular dislocations: coracoclavicular reconstruction with and without additional direct acromioclavicular repair. Knee Surg SportsTraumatol Arthrosc 2017; 25:2025-2031.

4. Yoon JP, Lee YS, Song GS, Oh JH. Morphological analysis of acromion and hook plate for the fixation of acromioclavicular joint dislocation. Knee Surg Sports TraumatolArthrosc2017; 25: 980-986.

5. Epstein D, Day M, Rokito A. Current concepts in the surgical management of acromioclavicular joint injuries. Bull NYU Hosp Jt Dis 2012; 70:11-24.

6. Weaver JK, Dunn HK. Treatment of acromioclavicular injuries, especially complete acromioclavicular separation. $J$ Bone Joint Surg Am. 1972; 54(6):11871194.

7. Jones HP, Lemos MJ, Schepsis AA. Salvage of failed acromioclavicular joint reconstruction using autogenous semitendinosus tendon from the knee. Surgical technique and case report. Am J Sports Med. 2001; 29:234-237.
8. Sharaby MMF, Mostafa MF. Sling reconstruction of acromioclavicular joint dislocation: is screw fixation necessary? The Egyptian Orthopaedic Journal 2016, 51:339-346.

9. Walz L, Salzmann GM, Fabbro T, Eichhorn $\mathrm{S}$, Imhoff $\mathrm{AB}$. The anatomic reconstruction of acromioclavicular joint dislocations using 2 Tight Rope devices: a biomechanical study. Am J Sports Med 2008; 36: 2398-2406.

10. ESENYEL CZ, ÖZTÜRK K, BÜLBÜL M, AYANOĞLU S, CEYLAN HH. Coracoclavicular ligament repair and screw fixation in acromioclavicular dislocations. Acta OrthopTraumatolTurc 2010; 44(3):194-198.

11. Bosworth BM. Complete acromioclavicular dislocation. $N$ Engl J Med 1941; 241:221225.

12. Harris RI, Wallace AL, Harper GD, Goldberg JA, Sonnabend DH, Walsh WR. Structural properties of the intact and the reconstructed coracoclavicular ligament complex. Am J Sports Med 2000; 28:103-8.

13. Shin SJ, Campbell S, Scott J, McGarry MH, Lee TQ. Simultaneous anatomic reconstruction of the acromioclavicular and coracoclavicular ligaments using a single tendon graft. Knee Surg Sports Traumatol Arthrosc 2014; 22:2216-2222.

14. Sobhy MH. Midterm results of combined acromioclavicular and coracoclavicular reconstruction using nylon tape. Arthroscopy 2012; 28(8):1050-1057.

15. Mohamed EL-Menawy. Acute acromioclavicular dislocations: results of coracoclavicular screw fixation. Egyptian Orthopedic Journal 2014, 49:38-42.

16. Greiner S, Braunsdorf J, Perka C, Herrmann $\mathrm{S}$, ScheZer S. Mid to long-term results of open acromioclavicular-joint reconstruction using polydioxansulfate cerclage augmentation. Arch Orthop Trauma Surg 2009; 129:735-740. 
إعادة بناء الأخرمي الترقوي والغرابي الترقوي بواسطة شريط النايلون مقابل المسمار الغرابي الترقوي الأخري في علاج الخلع الأخرمي الترقوي الحيط التراد

طارق محمد خليل، ماجد محمد سامي ابوالسعود، وائل احمد محمد نصار، محمد حسن صبحي، اشرف محمد السداوي و أحمد عيل مرسي خالدا.

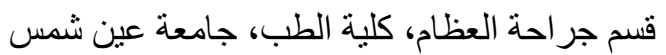

المقدمة و الهُف من الدراسة: تم وصف عدد من الأساليب الجر احية المختلفة لعلاج خلع المفصل الاخرمي الترقوى

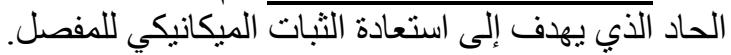

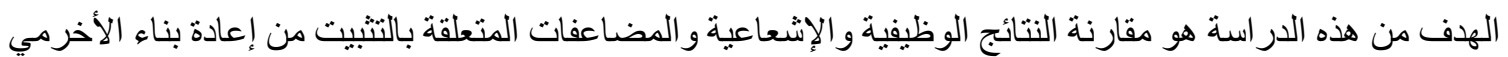

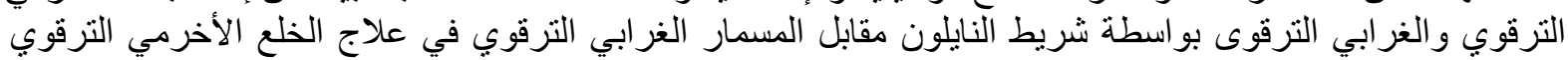

الحالاتوطرق البحث: أجري هذا البحث علي ثلاثين مريضا يعانون من خلع للمفصل الاخرمي الترقوي من النوع

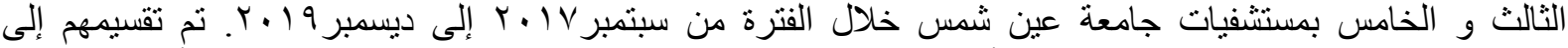

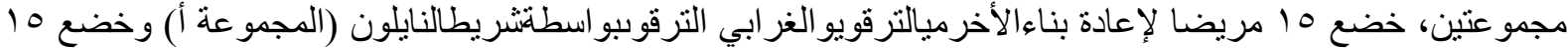

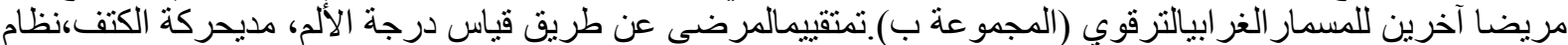

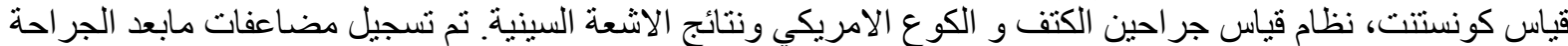
وتقييم وقت العودة إلى العمل. تم التقييم قبل الجر احة وفي كل متابعة لمدة لاتقل عن سنة.

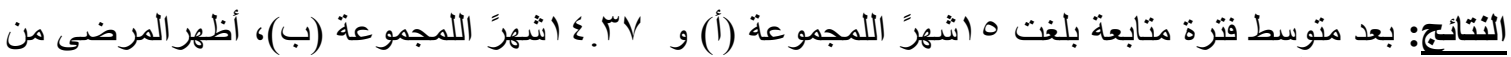

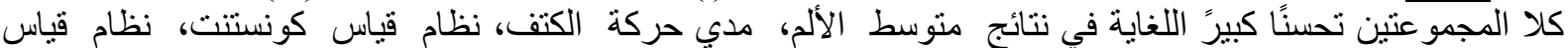

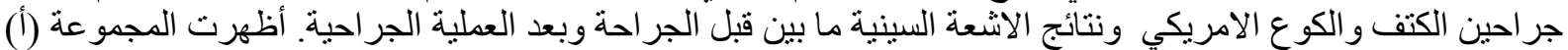

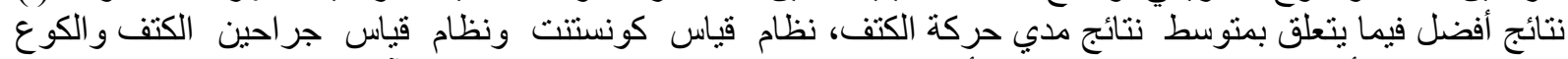

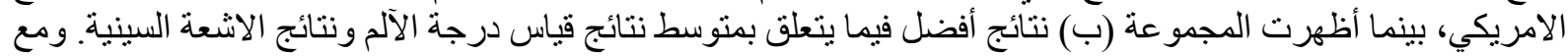
ذلك، لم يكن هناك فرق ذات دلالة إحصائية بين المجمو عتين.

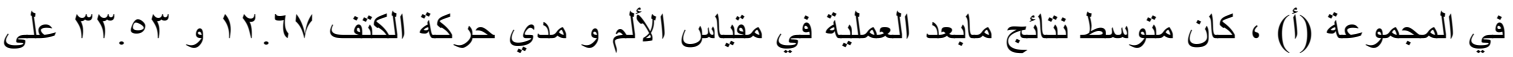

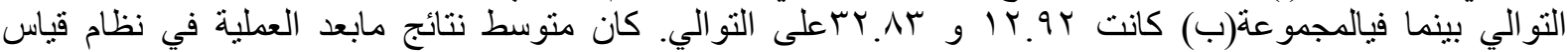

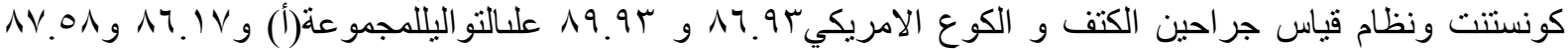

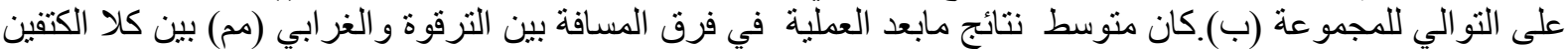

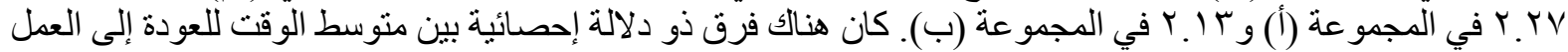

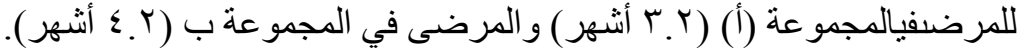

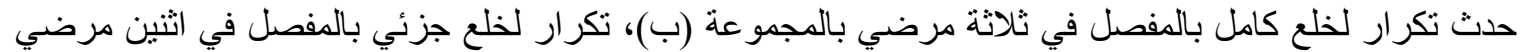

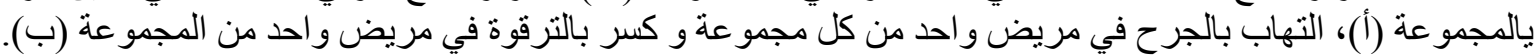
خلاصةًالبحث: يعد كل منإِ عادة بناء الأخرميالترقويو الغرابي الترقوى بواسطة شريطالنايلونو المسمار الغرابي

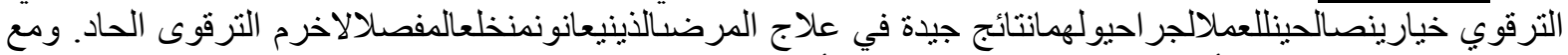

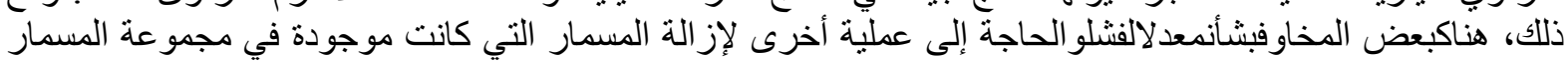

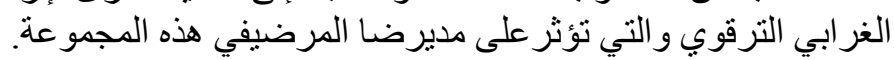

